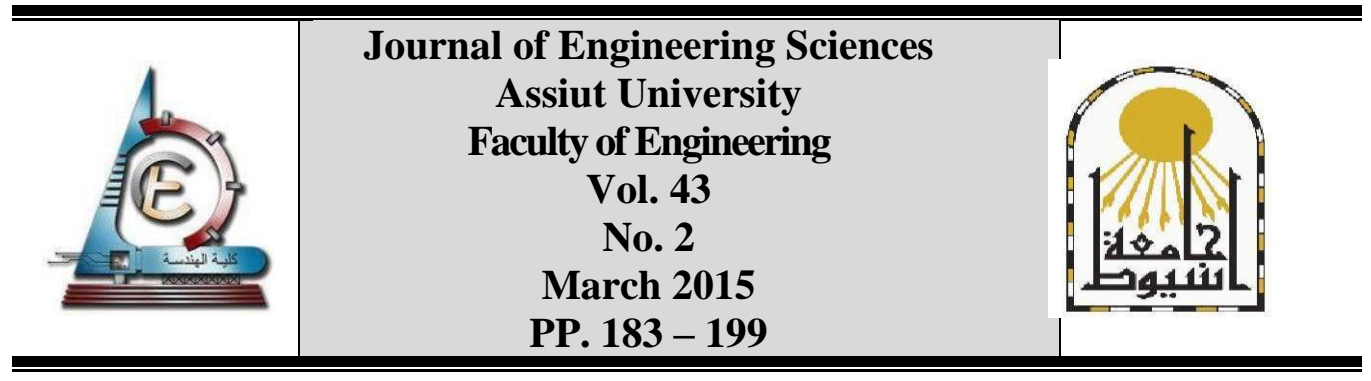

\title{
EFFECT OF LOCAL METAKAOLIN ON PROPERTIES OF CONCRETE AND ITS SULPHURIC ACID RESISTANCE
}

\author{
Mohamed M. Rashwan ${ }^{1}$, Abdel Rahman Megahed ${ }^{2}$, Mohamed Sayed Essa ${ }^{3, *}$ \\ 1, 2 staff in Civil Engineering Depart., Faculty of Engineering, Assiut University, Assiut, Egypt. \\ ${ }^{3}$ Civil Engineer, Zagazzige University, 2005.
}

(Received 24 March 2015; Accepted 28 April 2015)

\begin{abstract}
Recently, there is an energy crisis in Egypt. The Portland cement industry is a highly energy intensive process requiring about $112 \mathrm{k} . \mathrm{w}$ of energy-per ton of finished product. Therefore, the efforts should be made to find alternatives for Cement. Supplementary cementing materials (SCM) play an important role in the production of high strength and high performance concrete. In recent years worldwide, metakaolin (MK) has been studied because of its high pozzolanic properties. MK is obtained by the calcination of kaolinite. The raw material input in the manufacture of MK is kaolin. Although Egypt have a large reserve of kaolin however, MK is not widely produced and used due to the lack of adequate experiments. Therefore in these study local kaolins was thermally treated at specified conditions at $750^{\circ} \mathrm{C}$ for three hours to produce what so-called MK material.

This study investigates the influence of using two types of local metakaolin as supplementary cementing material on properties, strength and durability of concrete and compared with the performance of ordinary (control) and silica fume. The experimental study was carried out in two stages. The first stage consists of 14 concrete mixes from the two obtained types of metakaolin, MKA and MKB and in addition to silica fume (SF) with various percentage $(8 \%, 12 \%, 15 \%$ and $20 \%$ ) as partial replacement by cement weight to study fresh properties of concrete in terms of unit weight, compacting factor and slump (Superplasticizer Dosage), as well as the hardened properties in terms of compressive strength, water absorption and Porosity. The second stage in this research, investigated the effect of two metakaolins and comparing with silica fume as well as type of cement on concrete resistance to 3\% sulphuric acid attack by measuring the percentage of mass loss and percentage reduction in compressive strength after 30,60 and 90 days of acids immersion.

Results show that similar to silica fume, Egyptian metakaolin can be considered as an effective pozzolanic mineral admixture where, metakaolin replacement of cement is effective in improving the fresh and mechanical properties of concrete. The optimum dosage of metakaolin, as a partial cement replacement is 15 to $20 \%$ for the used fineness in this study at $\mathrm{W} / \mathrm{Cm}$ ratio 0.4 . It achieves an increase in compressive strength by $25 \%$ as compared to control ones, as well as it has the lowest water absorption. A beneficial effect was found by incorporating combination of two admixtures $20 \%$ silica fume with $15 \%$ metakaolin on concrete sulphuric acid resistance.
\end{abstract}

Keywords: Supplementary cementing materials, metakaolin, high pozzolanic properties, silica.

\footnotetext{
* Corresponding author.

Email address: engasmanty@yahoo.com
} 


\section{Introduction}

The use of cementing materials is very old. The ancient Egyptians used calcined impure gypsum. The Greeks and Romans used calcined limestone and later learned to add to lime and water, sand and crushed stone or brick and broken tiles. This was the first concrete in history [2]. The first documented use of MK was in 1962, when it was incorporated in the concrete used in the Jupia Darwin Brazil. It has been commercially available since the mid-1990s and currently costs approximately $\$ 500 /$ ton [3]. Metakaolin is a white ultrafine powdered form of anhydrous alumino-silicate derived from the calcination of raw kaolin. Calcination is a term referring to the controlled burning process at a specific temperature range, to obtain a quasiamorphous material. Dehydroxylation of kaolinite occurs at about $400-650 \mathrm{C}^{\circ}$ and as the temperature is increased to $550-900 \mathrm{C}^{\circ}$, the metakaolin decomposes into primary oxide. This thermal process activation or dehydroxylation, leads to the breakdown or partial breakdown of the crystal lattice structure, forming a phase transition which is highly disordered, amorphous and with pozzolanicity [4]. In [5], author presents a comprehensive overview of the previous works carried out on metakaolin sources and production. Where the author has collected all the researches that has investigated in the obtaining metakaolin from calcination of kaolin. The author concluded that the optimum temperature for heating kaolin in order to obtain MK with a high pozzolanic index is still different from one researcher to another. The heating period also is still exactly undetermined. The optimum temperature for heating kaolin to obtain MK may be in the range from $600 \mathrm{C}$ to $850 \mathrm{C}$ for $1-12 \mathrm{~h}$.

At [6], researchers reported that MK offered much better workability than did silica fume for the same mixture proportions. These mixtures contained 5, 10, or $15 \%$ replacement with either MK or silica fume, and a w/cm of 0.35. In addition, researchers at [7] reported that the dosage of superplasticizer required, in their study, increased with increasing MK content, to compensate for losses in workability. Vu et al., [8] reported that higher blending percentages resulted in a higher water demand to reach normal consistency. For the particular Vietnamese kaolin used in this study, setting times of pastes in the lower replacement range (10-20\% MK) were not significantly affected by blending. Beyond this range, the initial and final settling times increased by $15 \%$ and $10 \%$, respectively, likely due to the lower cement and higher water contents involved. Conversely, in a 2001 study.

SCM's such as metakaolin improve the compressive strength of concrete in two ways: reacting with $\mathrm{CH}$ crystals to create secondary $\mathrm{C}-\mathrm{S}-\mathrm{H}$ and by acting as filler. SCM's typically contain high amounts of alumina-silica and in a highly alkaline environment react with the $\mathrm{CH}$ to produce $\mathrm{C}-\mathrm{A}-\mathrm{S}-\mathrm{H}$ and reduce the porosity and significantly improve the strength of the concrete [9]. Both compressive and tensile strength of concretes incorporating MK. Compressive strength was found to increase substantially with increasing MK content. In samples with $15 \%$ replacement compressive strength had increased 51\% over controls [10]. Also at [4] authors studied the compressive strength of cement containing five metakaolins up to 180 days. It concluded that Metakaolin had a very positive effect on the cement strength after 2 days and specifically at 28 and 180 days. $10 \%$ metakaolin content seemed to be, generally, more favorable than $20 \%$. Siddique and Klaus [11] presented an overview of the work carried out on the use of MK as partial replacement of cement in mortar and concrete. The authors reported that MK enhances the early age mechanical properties as well as long-term strength properties of cement paste/mortar/concrete. Also, the partial replacement of cement with MK reduces the water 
penetration into concrete by capillary action. They also reported that durability of MK concrete increased with increasing the MK replacement level.

Poon [12] utilized mercury intrusion porosimetry (MIP) to evaluate porosity and pore size distribution of MK pastes. These pastes had lower porosity and smaller average pore diameters than the control and the silica fume pastes at all ages tested $(3,7 ; 28$, and 90 days). This indicates that MK is more effective than silica fume in the refinement of pore structure. These results are different than those reported by both Frias [13] and Khatib [14], who both found MK pastes to have $16 \%$ greater porosity than controls at 28 days. However, these previous studies were conducted at a w/cm of 0.55 , while the Poon et al, study was conducted with pastes prepared at a $w / \mathrm{cm}$ of 0.30 .

Conventional concretes produced using standard cements (Types I to V) are inadequate for preventing the degradation of concrete by sulphuric acid attack [15]. The literature review on the effect of SCMs on the concrete resistance to sulfuric acid attack is contradictory. For instance, Mehta [16] and Durning and Hicks [17] reported that the incorporation of silica fume increased the resistance of concrete to $1 \%$ sulfuric acid attack due to reduced calcium hydroxide content and lower permeability. On the other hand, Torii and Kawamura [18] investigated the effect of using silica fume and fly ash as partial replacement for cement on the resistance of concrete to a $2 \%$ solution of sulphuric acid. They concluded that such a partial replacement for cement could not effectively prevent the acid-type deterioration involving surface scaling and softening of mortar. Another study by, Hewayde et al. [19] they concluded that both silica fume and metakaolin enhanced the compressive strength and reduced the porosity of concrete, but only metakaolin improved the resistance to acid attack. Where a dosage of $15 \%$ metakaolin decreased the mass loss of concrete specimens due to immersion for 61days in sulphuric acid solutions with concentrations of $7 \%$ and $3 \%$ by $38 \%$ and $25 \%$, respectively.

\section{Experimental work}

An experimental program was conducted including two-laboratory Stages. The first Stage includes study the potential of two Egyptian metakaolins for use as supplementary cementing materials, in terms of slump, setting time, compressive strength, water absorption and Porosity. Also to evaluate the optimum percentage ratio of two metakaolin as a cement replacement in concrete. The second stage investigated the effect of metakaolin and comparing to that of silica fume as well as type of used cement on concrete resistance to sulphuric acid attack.

\subsection{Materials}

Local kaolin with high kaolinite content from Kalabsha quarry in Aswan (KA) and Abo zenima quarry in Sinai (KB) was thermally treated by an electric furnace at $750^{\circ} \mathrm{C}$ for a period of 3 hours to produce metakaolin. The chemical compositions of the two kaolins (KA) and (KB) are presented in Table (1). After calcination, the two kaolins were ground to achieve lowest possible fineness. The materials used in this investigation were locally sourced and they satisfied the requirements of respective Egyptian Standards. Table (2) presents the results of chemical compositions and Physical Properties of the two cements, an ordinary Portland cement (OPC) and a Sulphate resistance cement (SRC), a silica fume (SF) and two obtained local metakaolin (MKA) (MKB) used in this research program. Silica fume used in this study was provided from Egyptian Ferro Alloys Company (EFACO) in Edfu, 
Aswan. Clean natural siliceous sand from Bousra quarries in Assiut was chosen as fine aggregates with maximum aggregate size of $4.75 \mathrm{~mm}$. Coarse aggregate used in this research was natural gravel from also Bousra quarries with maximum aggregate size of $40 \mathrm{~mm}$ were used. The coarse aggregates have a specific gravity, crushing value and water absorption of $2.5,11.75$ and $0.58 \%$, respectively, and the fine aggregate has water absorption of $0.73 \%$, fineness modulus of 2.42 and a specific gravity of 2.55. Potable water was used for casting and curing of all concrete specimens. The Sulphonated naphthalene formaldehyde based Superplasticizer (ADDICRETE B-V-F) having a density of $1.21 \mathrm{t} / \mathrm{m}^{3}$ was employed to achieve the desired workability.

Table 1.

The chemical analysis of local raw kaolins

\begin{tabular}{|c|c|c|c|c|c|c|c|c|c|}
\hline $\begin{array}{c}\text { Chemical } \\
\text { analysis (\%) }\end{array}$ & $\mathrm{SiO}_{2}$ & $\mathrm{Al}_{2} \mathrm{O}_{3}$ & $\mathrm{Fe}_{2} \mathrm{O}_{3}$ & $\mathrm{CaO}$ & $\mathrm{MgO}$ & $\mathrm{TIO}_{2}$ & $\mathrm{~K}_{2} \mathrm{O}$ & $\mathrm{Na}_{2} \mathrm{O}$ & $\mathrm{SO}_{3}$ \\
\hline Kaolin (KA) & 53.0 & 37.3 & 2.5 & 1.6 & 0,14 & 3.6 & 0.04 & 0.18 & 0.037 \\
\hline Kaolin (KB) & 57.6 & 31.2 & 3.2 & 0.7 & 0,15 & 2.2 & 0.3 & 0.53 & 0.032 \\
\hline
\end{tabular}

Table 2.

Chemical composition and Physical properties of cements and SCMs

\begin{tabular}{|l|c|c|c|c|c|c|c|c|c|c|c|c|}
\hline & \multicolumn{9}{|l|}{ Chemical analysis (\%) } \\
\cline { 2 - 13 } & $\mathrm{SiO}_{2}$ & $\mathrm{Al}_{2} \mathrm{O}_{3}$ & $\mathrm{Fe}_{2} \mathrm{O}_{3}$ & $\mathrm{CaO}$ & $\mathrm{MgO}$ & $\mathrm{TIO}_{2}$ & $\mathrm{~K}_{2} \mathrm{O}$ & $\mathrm{Na}_{2} \mathrm{O}$ & $\mathrm{SO}_{3}$ & $\begin{array}{c}\text { Specific } \\
\text { gravity }\end{array}$ & $\begin{array}{c}\text { (S.S.A) } \\
\left(\mathrm{cm}^{2 / g}\right)\end{array}$ & $\begin{array}{l}\text { Appearance } \\
\end{array}$ \\
& & & & & & & & & & & & \\
\hline OPC & 20.8 & 4.82 & 4.0 & 62.6 & 1.40 & - & 0.24 & 0.4 & 2.54 & 3.15 & 10100 & Gray \\
\hline SRC & 20.7 & 4.50 & 5.20 & 62.7 & 1.50 & - & 0.23 & 0.43 & 2.10 & 3.15 & 10170 & Gray \\
\hline SF & 96.8 & 0.41 & 1.30 & 0.98 & 0.14 & - & 0.87 & & & 2.20 & 139723 & Dark gray \\
\hline MKA & 53.0 & 37.3 & 2.5 & 1.6 & 0,14 & 3.6 & 0.04 & 0.18 & 0.037 & 2.40 & 60750 & White to gray \\
\hline MKB & 57.6 & 31.2 & 3.2 & 0.7 & 0,15 & 2.2 & 0.3 & 0.53 & 0.032 & 2.40 & 55310 & Light pink \\
\hline
\end{tabular}

* Specific surface area by nitrogen adsorption technique using the method of BET.

\subsection{Concrete proportions and specimen preparation}

The first stage consists of fourteen concrete mixtures with a total of 182 cubes and divided into five groups. The first mix is the control concrete mixt (PC) with pure ordinary Portland cement without admixtures. The purpose of this group is to be the reference of the study. The second mix (SR) is the same of first mix but by using sulphate resistance cement; this mix was made to investigate the cement type effect in the concrete properties. The other 12 mixes were based on the control mix but involved the use of admixtures, two metakaolins (MKA), (MKB) and silica fume (SF) with different dosages. The third group contains mixes with four levels of silica fume $(8 \%, 12 \%, 15 \%$ and $20 \%$ by mass of cement). The fourth and fifth group was designed to study the effect of the two metakaolins (MKA) and (MKB) dosages $(8 \%, 12 \%, 15 \%$ and $20 \%$ by mass of cement) on concrete properties.

All mixes were designed to have a constant water-cementitious materials ratio $(\mathrm{w} / \mathrm{cm})$ of 0.4 and mix proportions are presented in table (3). A high-range, water-reducing admixture (superplasticiser) was used to maintain the workability of all mixtures within the same range (slump of $10 \pm 2 \mathrm{~cm}$ ) for the ease of handling, placing, and consolidation in all concrete mixtures. The super-plasticizer was adjusted at the time of mixing to achieve the specified slump. 
Mohamed Sayed Essa et al., Effect of local metakaolin on properties of concrete and its sulphuric...

Each mixture of the fourteen mixtures will be moulded into thirteen standard cubes $15^{*} 15^{*} 15 \mathrm{~cm}$ and each mix will be tested just after mixing for unit weight, compacting factor and slump test for the determination of required superplasticiser amount. For the determination of the hardened properties, Nine of the 13 specimens from each mixture were used to determine the compressive strength at 7,28 and 90 days (three specimens tested at each date). Three specimens from each mix were used for water absorption tests. Small samples were taken from the remaining specimen for each mixture to carry out porosity tests which were carried out by using the nitrogen adsorption method.

From the first stage results, the optimum dosages of two metakaolin and silica fume as a partial replacement of cement weight, on the compressive strength of concrete mixtures are used to investigate its effect on the concrete resistance to sulphoric acid attack.

Eight concrete mixes (PC), (SR), (MKA20), (MKB15) and (SF20) in addition to three concrete mixes (FB), (KBS15) and (SFS20) were added as described in table (3). Where (FB) mix were used to determine the effect of two additions SF and MKB together on concrete resistance to sulphoric acid. As well concrete mixes (KBS15) and (SFS20) were used to predict the effect of sulphate resistant cement with additions SF, MKB on concrete resistance to sulphoric acid. These mixes have been prepared and casted with the same specifications and procedures used in the second stage. Each mixtures consisted of 12 standards $15^{*} 15^{*} 15$ cubes, were immersed in $3 \%$ by volume sulphoric acid $\left(\mathrm{H}_{2} \mathrm{SO}_{4}, \mathrm{PH} \approx\right.$ 0.6). The sulphuric acid tests programme indecating measurements, reduction in compressive strength $\%$ and Mass loss \% were performed at 30, 60, and 90 days of each acids solutions immersion, where three specimens at each testing date and these tests will be explained in detail below. The remaining three specimens for each mixture were prepared backup.

Table 3.

Proportions of various Concrete Mixtures.

\begin{tabular}{|c|c|c|c|c|c|c|c|c|c|c|c|c|c|}
\hline \multirow[b]{2}{*}{$\begin{array}{c}\text { Group } \\
\text { No. }\end{array}$} & \multirow[b]{2}{*}{$\begin{array}{l}\text { Mix } \\
\text { code }\end{array}$} & \multicolumn{2}{|c|}{ Cement type } & \multirow[b]{2}{*}{ W/cm } & \multirow{2}{*}{$\begin{array}{l}\text { Water } \\
\mathrm{Kg} / \mathbf{m}^{3}\end{array}$} & \multirow[b]{2}{*}{$\begin{array}{l}\text { Rep, } \\
\text { Level }\end{array}$} & \multirow[b]{2}{*}{$\begin{array}{c}\mathrm{SF} \\
\mathrm{Kg} / \mathrm{m}^{3}\end{array}$} & \multirow[b]{2}{*}{$\begin{array}{l}\text { MIKA } \\
\mathbf{K g} / \mathbf{m}^{3}\end{array}$} & \multirow[b]{2}{*}{$\begin{array}{l}\text { MKB } \\
\mathrm{Kg} / \mathrm{m}^{3}\end{array}$} & \multirow[b]{2}{*}{$\begin{array}{l}\text { Gravel } \\
\mathbf{K g} / \mathbf{m}^{3}\end{array}$} & \multirow[b]{2}{*}{$\begin{array}{l}\text { sand } \\
\mathrm{Kg} / \mathrm{m}^{3}\end{array}$} & \multirow[b]{2}{*}{$\begin{array}{c}\text { Slump } \\
\mathbf{c m}\end{array}$} & \multirow{2}{*}{$\begin{array}{c}\text { Super- } \\
\text { plast } \\
\mathbf{L} / \mathbf{m}^{3}\end{array}$} \\
\hline & & $\begin{array}{c}\text { O.P.C } \\
\mathrm{Kg} / \mathrm{m}^{3}\end{array}$ & $\begin{array}{l}\text { S.R.C } \\
\mathrm{Kg} / \mathbf{m}^{3}\end{array}$ & & & & & & & & & & \\
\hline $\begin{array}{c}\text { Group } \\
\text { no.1 }\end{array}$ & PC & 400 & - & 0.40 & 160 & - & - & - & - & 1158 & 637 & 10 & 2 \\
\hline 呑 & SR & - & 400 & 0.40 & 160 & - & - & - & - & 1158 & 637 & 10 & 2 \\
\hline \multirow{4}{*}{ 高皇 } & SF8 & 368 & - & 0.40 & 160 & $8 \%$ & 32 & - & - & 1151 & 633 & 11 & 2.75 \\
\hline & SF12 & 352 & - & 0.40 & 160 & $12 \%$ & 48 & - & - & 1147 & 631 & 9 & 4.10 \\
\hline & SF15 & 340 & - & 0.40 & 160 & $15 \%$ & 60 & - & - & 1145 & 630 & 10 & 5.48 \\
\hline & SF20 & 320 & - & 0.40 & 160 & $20 \%$ & 80 & - & - & 1140 & 627 & 9 & 6.25 \\
\hline \multirow{4}{*}{ 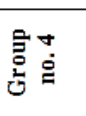 } & MKA8 & 368 & - & 0.40 & 160 & $8 \%$ & - & 32 & - & 1153 & 634 & 11 & 2.72 \\
\hline & MKA12 & 352 & - & 0.40 & 160 & $12 \%$ & - & 48 & - & 1150 & 633 & 9 & 3.30 \\
\hline & MKA15 & 340 & - & 0.40 & 160 & $15 \%$ & - & 60 & - & 1148 & 632 & 10 & 3.56 \\
\hline & MKA20 & 320 & - & 0.40 & 160 & $20 \%$ & - & 80 & - & 1145 & 630 & 11 & 3.84 \\
\hline \multirow{4}{*}{ 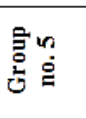 } & MKB8 & 368 & - & 0.40 & 160 & $8 \%$ & - & - & 32 & 1153 & 634 & 11 & 2.72 \\
\hline & MKB12 & 352 & - & 0.40 & 160 & $12 \%$ & - & - & 48 & 1150 & 633 & 9 & 3.30 \\
\hline & MKB15 & 340 & - & 0.40 & 160 & $15 \%$ & - & - & 60 & 1148 & 632 & 10 & 3.65 \\
\hline & MKB20 & 320 & - & 0.40 & 160 & $20 \%$ & - & - & 80 & 1145 & 630 & 12 & 3.90 \\
\hline \multirow{3}{*}{ 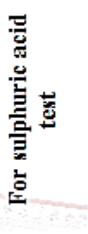 } & FB & 320 & - & 0.40 & 160 & $\begin{array}{c}\text { SF20 } \\
+ \\
\text { MKB } \\
\mathbf{1 5}\end{array}$ & 80 & - & 60 & 1140 & 605 & 10.5 & 6.50 \\
\hline & SFS20 & - & 320 & 0.40 & 160 & SF20 & 80 & - & - & 1140 & 627 & 9 & 6.25 \\
\hline & KBS15 & - & 340 & 0.40 & 160 & $\begin{array}{c}\text { MKB } \\
15\end{array}$ & - & - & 60 & 1148 & 632 & 10 & 3.90 \\
\hline
\end{tabular}




\subsection{Test procedure}

\subsubsection{Early age properties}

Early age properties of and concrete, including slump, compacting factor and unit weight were measured. Slump was measured according (ESS 1658/1989). Super-plasticizer was used as necessary in order to achieve a target slump of $10 \pm 2 \mathrm{~cm}$ for all mixtures. Unit weight was calculated based on an average of three $3 \times 4$ " $(76 \times 100 \mathrm{~mm})$ concrete cylinders.

\subsubsection{Compressive strength test}

Compressive strength tests were performed at 7,28 and 90 days using Testing machine (150 ton capacity) for the concrete cubes. The load was axially transmitted from the head of testing machine to the tested cubes through two steel plates.

\subsubsection{Water absorption test}

Three specimens from each fourteen concrete mixes as mention above were used for water absorption tests. At the end of the 28-day curing period for concrete specimens used in the water absorption tests, the specimens were oven dried at $105^{\circ} \mathrm{C}$ until constant weight, cooled at room temperature, weighed using an electronic scale (accuracy of $\pm 0.01 \mathrm{~g})(\boldsymbol{W I})$. After wards it immersed into the water tank for 24 hours the surface dried and then weighed once more (W2). The percentage of water absorption calculated by the following equation

$$
\% \text { water absorption }=\frac{w 2-w 1}{w 1} * 100
$$

\subsubsection{Porosity measurement test}

The nitrogen adsorption technique used in this study was used to measure specific surface area according to the BET(Brunauer, Emmett, Teller) method [20], while pore size distribution was measured according to the BJH (Barrett, Joyner, Halenda) method [21]. Total porosity, specific surface area and pore size distribution were measured in Small samples were taken from fresh broken concrete for selected concrete mixtures (PC), (MKA20), (MKB15) and (SF20) after 28 days of age. Nitrogen adsorption was performed by NOVA-3000 series apparatus in Surface Area Lap in Faculty of Science, Assiut University.

\subsubsection{Sulphuric acid test measurements}

In this investigation. A sulphuric acid of $3 \%$ concentration $\left(\mathrm{H}_{2} \mathrm{SO}_{4}, \mathrm{PH} \approx 0.6\right)$ were chosen for accelerated laboratory investigation to simulate the aggressive environment of some sewer and treatment structures. The solutions of 3\% sulphuric acid were prepared by mixing concentrated acids with a predetermined amount of Tap water. The $\mathrm{pH}$ levels of the acid solutions were monitored weekly using a portable digital $\mathrm{pH}$ meter (standard error \pm $0.05)$. Concentrated acid was periodically added to the solutions to maintain the $\mathrm{pH}$ levels within an acceptable range of the designated concentrations also refreshed acid solution monthly. Polyvinyl chloride (PVC) container with diameter of $90 \mathrm{~cm}$ was used to carry out acid solution and immersed the concrete specimens on it.

Selected concrete mixes were used for the sulphuric acid test. At the end of the 28-day, the specimens were air dried for five hour then weighted using an electronic scale (accuracy of $\pm 0.01 \mathrm{~g}, \mathrm{M} 1$, initial mass) and then immersed into the acid solutions.

The effect of solutions of $3 \%$ sulphuric acid on deterioration and performance of selected concrete mixtures was photographically recorded during the exposure period before testing of the specimens. The degree of deterioration was also evaluated by measuring the mass loss and reduction in compressive strength. The percentage of mass 
Mohamed Sayed Essa et al., Effect of local metakaolin on properties of concrete and its sulphuric...

loss and percentage reduction in compressive strength measurements were performed at 30, 60 and 90 days of acids immersion; At each date the specimens were removed from the acid solution, carefully washed with tap water, brushed gently with a wire brush then airdried five hour before mass measurement $\left(\mathrm{M}_{2}\right)$ and compressive strength testing $\left(\mathrm{F}_{\mathrm{C} 2}\right)$.

The mass change of a sample in percentage to the initial mass is a widely used indicator for assessment of the deterioration of concrete subjected to acid attack. The percentage of mass loss at each date was calculated according to the following equation:-

$\%$ Mass loss $=\frac{M 1-M 2}{M 1} * 100$

Where, $M_{1}$ is initial mass the specimen's mass before immersion and $M_{2}$ is the specimen's mass after immersion in acids solution.

The compressive strength of concrete specimens after exposure to sulphuric acid solutions was also tested at the 30,60 and 90 day immersion period to determine the relationship between the reduction in compressive strength of concrete specimens and their mass loss. The reduction in compressive strength of the concrete specimens was calculated as follows

Reduction in compressive strength\% $=\frac{F c 1-F c 2}{F c 1} * 100$

Where $\mathrm{Fc}_{1}$ is compressive strength at 28 days water curing and $\mathrm{Fc}_{2}$ is compressive strength after days of immersion in acid solution.

\section{Experimental results and discussions}

\subsection{Properties of fresh concrete}

To achieve a target slump of $(10 \pm 2 \mathrm{~cm})$, superplasticizer was required for all concrete mixtures, even in the control mixture superplasticizer was used at a dosage $2 \mathrm{l} / \mathrm{m}^{3}$. Superplasticizer dosage requirements $\left(1 / \mathrm{m}^{3}\right)$ of concrete at different ratio of cement replacement by SCMs (MKA, MKB and SF), compacting factors and density of concrete mixtures are given in table (4). Figure (1) shows the effect of MKA,MKB and SF replacement ratios on superplasticizer dosage, it can be noticed that, mixes containing either of the metakaolins (MKA and MKB) required less superplasticizer than that containing silica fume. Both metakaolins (MKA and MKB) approximately required the same superplasticizer dosage at the same ratio of cement replacement. In general it was found that compared to the control mixture, metakaolin replacement increased superplasticizer dosage rates increased. It was also observed that at $20 \%$ replacement incorporation of Silica fume required $60 \%$ more than the amount used with both metakaolins. This result is in agreement with other studies which showed that MK offers much better workability than SF [6].

\subsection{Concrete hardened properties}

\subsubsection{Water absorption}

Fourteen concrete mixes were used for water absorption tests after end of the 28-day curing. Figure (2) shows the relation between admixture type ( SF, MKA and MKB ) at different replacement ratios and water absorption\%. It was clearly evident from the results that both metakaolin and silica fume at different replacement ratios were found to eliminate the water absorption of concrete when compared with concrete made with OPC. The optimum dosage of MKA, MKB and SF on concrete water absorption was $20 \%, 15 \%$ 
190

JES, Assiut University, Faculty of Engineering, Vol. 43, No. 2, March 2015, pp. 183 - 199

and $20 \%$, respectively. Also both metakaolin at different replacement ratios showed better performance than SF on concrete water absorption.

Table 4.

Fresh properties of all tested concrete mixtures

\begin{tabular}{|c|c|c|c|c|c|c|}
\hline \multicolumn{3}{|c|}{ Concrete mix } & $\begin{array}{l}\text { Slump } \\
(\mathrm{cm})\end{array}$ & $\begin{array}{c}\text { Superplasticizer } \\
\text { dosage } L / \mathrm{m}^{3}\end{array}$ & $\begin{array}{l}\text { Compacting } \\
\text { factor }\end{array}$ & $\begin{array}{l}\text { Density } \\
\left(\text { ton } / \mathrm{m}^{3} \text { ) }\right.\end{array}$ \\
\hline \multicolumn{3}{|c|}{$\overline{\mathrm{PC} \text { (control) }}$} & 10 & 2 & 0.96 & 2.270 \\
\hline \multicolumn{3}{|c|}{ SR } & 10 & 2 & 0.95 & 2.274 \\
\hline \multicolumn{3}{|c|}{ SF8 } & 11 & 2.75 & 0.95 & 2.265 \\
\hline \multicolumn{3}{|c|}{ SF12 } & 9 & 4.10 & 0.97 & 2.263 \\
\hline \multicolumn{3}{|c|}{ SF15 } & 10 & 5.48 & 0.96 & 2.257 \\
\hline \multicolumn{3}{|c|}{ SF20 } & 9 & 6.25 & 0.94 & 2.244 \\
\hline \multicolumn{3}{|c|}{ MKA8 } & 11 & 2.72 & 0.95 & 2.271 \\
\hline \multicolumn{3}{|c|}{ MKA12 } & 9 & 3.30 & 0.95 & 2.271 \\
\hline \multicolumn{3}{|c|}{ MKA15 } & 10 & 3.56 & 0.97 & 2.272 \\
\hline \multicolumn{3}{|c|}{ MKA20 } & 11 & 3.84 & 0.96 & 2.273 \\
\hline MKB8 & 11 & 2.70 & \multicolumn{2}{|c|}{0.97} & \multicolumn{2}{|l|}{2.271} \\
\hline MKB12 & 9 & 3.30 & \multicolumn{2}{|c|}{0.96} & \multicolumn{2}{|l|}{2.272} \\
\hline MKB15 & 10 & 3.65 & \multicolumn{2}{|c|}{0.97} & \multicolumn{2}{|l|}{2.273} \\
\hline MKB20 & 12 & 3.90 & \multicolumn{2}{|c|}{0.97} & \multicolumn{2}{|l|}{2.278} \\
\hline
\end{tabular}

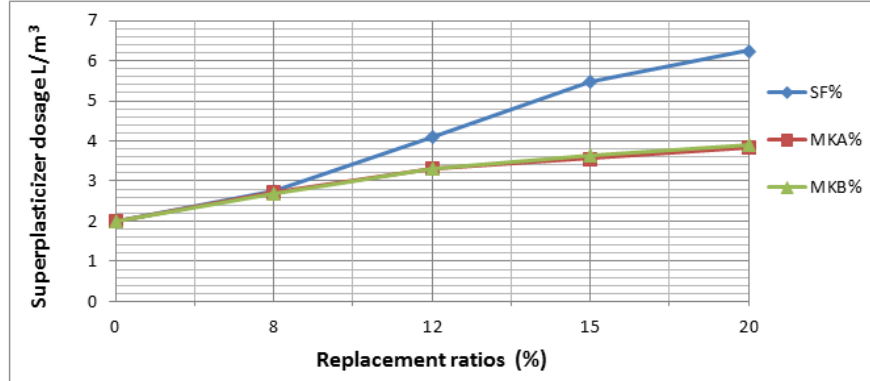

Fig. 1. Effect of replacement ratios on superplasticizer dosag

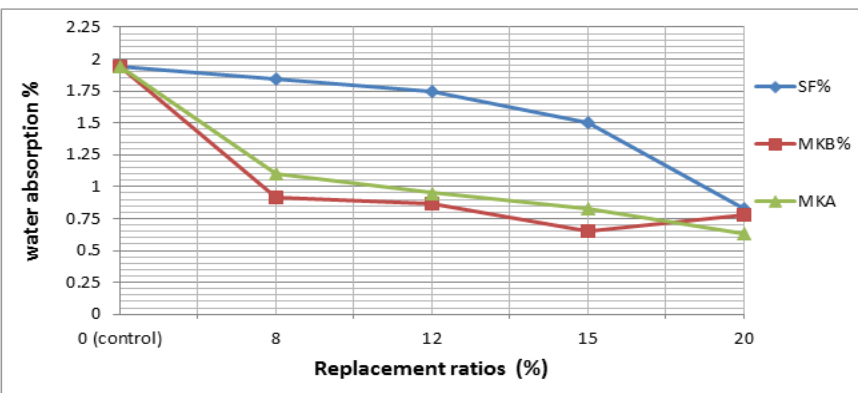

Fig. 2. Concrete water absorption $\%$ at different Replacement ratios of SF, MKA and MKB

\subsubsection{Porosity measurement}

The test results of BET specific surface area, total porosity, and pore size distribution for selected concrete mixtures, control (PC), (MKA20), (MKB15) and (SF20) after 28 days of age are given in table (5). It shows that both concretes containing metakaolin MKB15\%, MKA20\% and silica fume SF20\% exhibited a slightly higher surface areas 
Mohamed Sayed Essa et al., Effect of local metakaolin on properties of concrete and its sulphuric...

than control mixture. It was clear that, the concretes containing two type of metakaolin and silica fume had higher porosity and smaller average pore diameters than the control concrete. The concrete mix SF20\% had the highest porosity and smallest average pore diameter, where the increase in the porosity of $40 \%$ and the reduction on pore diameter by $13 \%$ compared with that for control. Also the concrete mixes containing both metakaolin, MKB15\% and MKA20\% had an increase on porosity about $36 \%$ and $21 \% \%$ and the reduction on pore diameter by $11 \%$ and $7.7 \%$, respectively than control mixture. Clearly notes that metakaolin have the same behavior of silica in the concrete porosity.

\section{Table 5.}

Nitrogen adsorption BET specific surface area, total porosity, and pore size distribution results for concrete mixtures.

\begin{tabular}{|c|c|c|c|}
\hline Mix & BET specific surface area $\left(\mathrm{m}^{2} / \mathrm{gm}.\right)$. & $\begin{array}{c}\text { Total porosity } \\
\left(\mathrm{mm}^{3} / \mathrm{gm} .\right) .\end{array}$ & $\begin{array}{c}\text { Average Pore } \\
\text { diameter }(\AA) .\end{array}$ \\
\hline PC (control, 0\%) & 5.40 & 7.94 & 66.02 \\
\hline MKB15\% & 6.72 & 10.8 & 58.83 \\
\hline MKA20\% & 6.67 & 9.59 & 60.92 \\
\hline SF20\% & 6.94 & 11.08 & 57.31 \\
\hline
\end{tabular}

These results may be due to the fact that both silica fume and metakaolin powder have high fineness, very small particle size and also pozzolanic reaction products $\mathrm{C}-\mathrm{S}-\mathrm{H}$ leading to a decrease in solid volume as well as an increase in number of very small pores and thus an increase in porosity. These results agree with what has been reported in the literature by khatib [14].

\subsubsection{Concrete compressive strength}

A significant increase in compressive strength as compared to the control concrete mix which was expected for silica fume concrete mixes with percentages $(8 \%, 12 \%, 15 \%$ and $20 \%$ ) as partial replacement of cement by weight, these results are shown in Figure (3). The practical optimum percentage of silica fume which gives the maximum compressive strength is $20 \%$. Comparing to control mix. The dosage of $20 \%$ silica fume resulted in an increase in the compressive strength of concrete specimens at 7, 28 and 90 days by 18.6, 25 and $47 \%$, respectively.

As well figure (4) and (5) shows the effect of various dosages of MKB and MKA (8\%, $12 \%, 15 \%$ and $20 \%$ ) as partial replacement of OPC by weight, on the compressive strength of concrete at the ages 7, 28 and 90 days. From figure (4) it clearly shows that, the highest compressive strength after 28 obtained was $447 \mathrm{~kg} / \mathrm{cm}^{2}$ at cement replacement with MKB by $15 \%$, an increase $23 \%$ when compared to that for the control mix. For this, the dosage of $15 \% \mathrm{MKB}$ deserves to be the optimum ratio for adding MKB as partial replacement of OPC by weight, on compressive strength of concrete. This confirms our findings that, cement replacement with MKB by $15 \%$ is the optimum ratio in the water absorption test.

As for concrete mixes containing MKA, the optimum ratio of MKA which gives the maximum compressive strength is $20 \%$, with increase in compressive strength of $13 \%$ at 28 days and $24 \%$ at 90 days comparing to that for the control concrete mix. this finding is also in agreement with those reported in this study, $20 \%$ of MKA is the best ratio in water absorption test. 


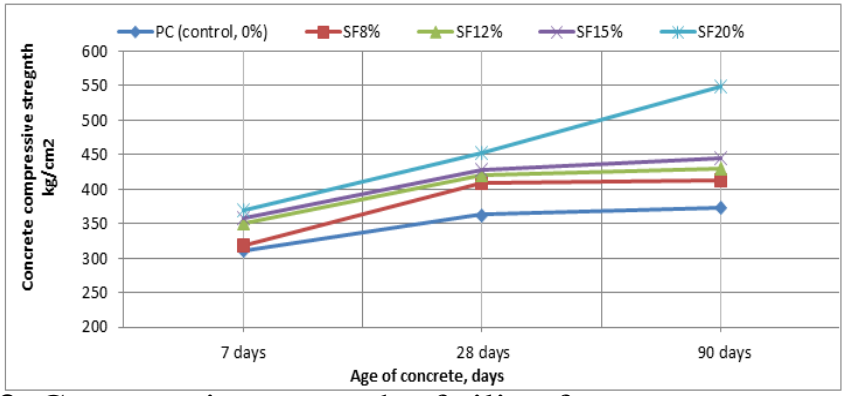

Fig. 3. Compressive strength of silica fumes concrete mixtures.

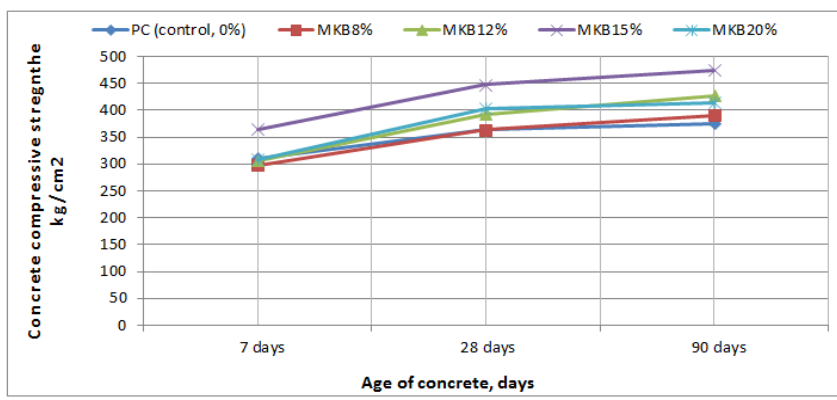

Fig. 4. Compressive strength of metakaolin (MKB) concrete mixtures

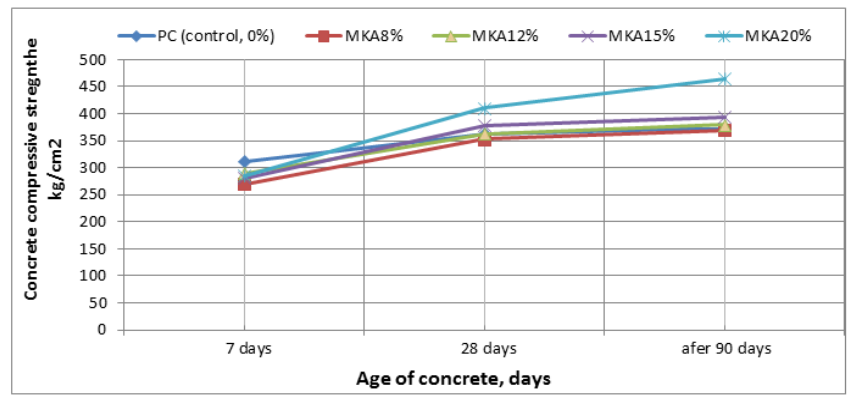

Fig. 5. Compressive strength of metakaolin (MKA) concrete mixtures.

Figure (6) (a, b and c) illustrates a comparison between effect of silica fume (SF) and two used types of metakaolin (MKA\&MKB) with different replacement ratios on concrete compressive strength (a) after 7, (b) after 28 and (c) after 90 days, respectively.

It can be observed from figure (6-a) that, after 7 days curing period, when adding SF to cement concrete mixes as partial replacement, the $8 \%, 12 \%, 15 \%$ and $20 \%$ addition, an increase was recorded in compressive strength of $2.7 \%, 12.5 \%, 15.1 \%$ and $18,6 \%$ more than the control mixture. While the incorporation of MKA is accompanied with a decreased in compressive strength at all replacement levels by $13.2 \%, 6.75 \%, 9.8 \%$ and $14.8 \%$ for a replacement ratio $8 \%, 12 \%, 15 \%$ and $20 \%$, respectively compared to that for control mix. Also the incorporation of $8 \%, 12 \%$ and $20 \%$ of MKB results in a decrease in the compressive strength by $4.2 \%, 1,4 \%$ and $0.96 \%$, respectively, meanwhile $15 \%$ of MKB recorded an increase in compressive strength equals $17 \%$ more than that for the control mix.

From figure (6-b) it was clearly evident that, similar to silica fume, both metakaolin MKA and MKB has a slight to moderate positive effect on compressive strength after 28 days. The highest compressive strength obtained when cement replacement with SF, where the increase on compressive strength equal $13 \%, 15.7 \%, 18.2$ and $25 \%$ at replacement ratio 
Mohamed Sayed Essa et al., Effect of local metakaolin on properties of concrete and its sulphuric...

of $8 \%, 12 \%, 15 \%$ and $20 \%$, respectively compared to the control mix. MKB concrete mixtures showed the second highest concrete compressive strength after SF mixes, where the increase on compressive strength equal $8.3 \%, 23 \%$ and $10.7 \%$ at replacement ratio of $12 \%, 15 \%$ and $20 \%$, respectively. Also adding $15 \%$ and $20 \%$ of MKA increased compressive strength by $4.3 \%$ and $13 \%$, respectively than that for control mix.

After 90 days curing period it can be observed from figure (6-c) that, the rate of increase in compressive strength almost similar to that after 28 days, but the rate of increase is evident at the optimum ratio of SF and MKA, where the concrete mixture containing of $20 \%$ of the SF recorded the highest increase in compressive strength, reaching $47 \%$ more than control mixture followed by $15 \%$ of $\mathrm{MKB}$, an increase of $27 \%$ and then $20 \%$ of MKA recorded increase in compressive strength equal $24 \%$ higher than that for the control mix.

It should be noted that, the compressive strength of metakaolin concrete mixes is initially lower than that for both control and silica fume mixes, this is may be due to low degree of fineness of used metakaolin compared to that of silica fume, which commonly leading to reduce the filler effect and slow rate of the pozzolanic reaction between metakaolin and $\mathrm{CH}$ produced by the hydration of cement. However, with the time passage, the pozzolanic reaction products $(\mathrm{C}-\mathrm{S}-\mathrm{H}$ and $\mathrm{C}-\mathrm{A}-\mathrm{H})$ have improved significantly the strength on the long term run. Finally, the combination of $20 \%$ of SF as partial replacement of cement and $15 \%$ of $\mathrm{MKB}$ as an addition in the concrete mixt (FB) resulted in a higher compressive strength compared to all mixes studied in this research, where the increase was equal $43.5 \%$ at 28 days and $58 \%$ at 90 days of age. This indicates that the combination of SF with MKB have a beneficial and best effect on increasing concrete compressive strength.

\subsection{Effect of sulphuric acid attack on durability of concrete}

\subsubsection{Visual inspection of concrete specimens}

Typical surface appearances of the cube samples of selected mixtures (PC), (SR), (MKA20), (MKB15), (SF20), (KBS15), (SFS20) and (FB) after 90 days immersion in 3\% sulphuric acid are shown in Fig. (7).

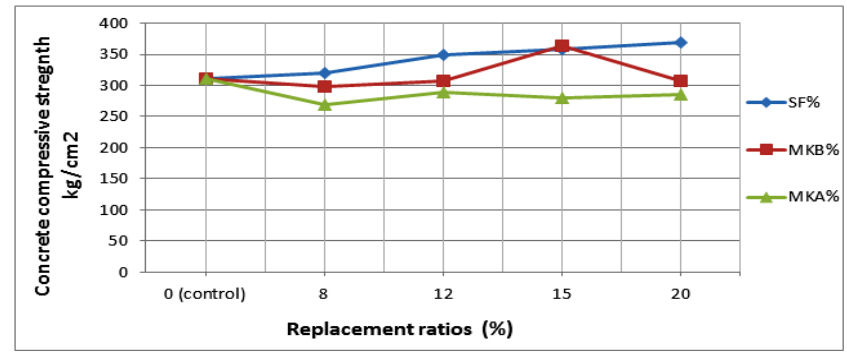

(a) 7 days

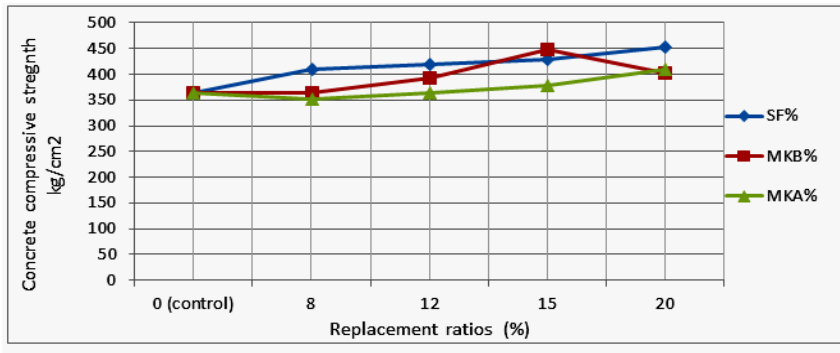

(b) 28 days 


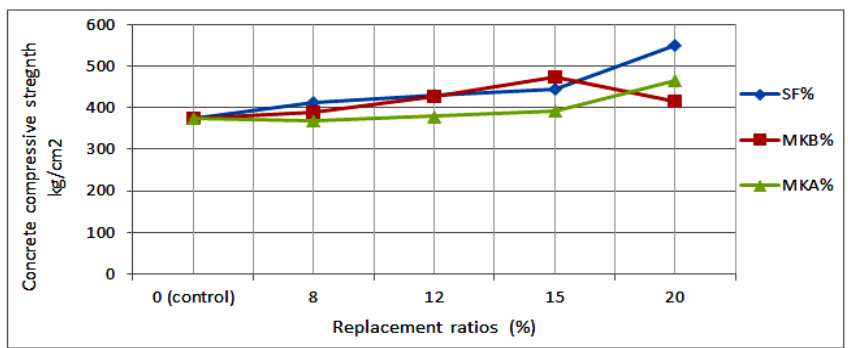

(c) 90 days

Fig. 6. Comparison between effect of (SF), (MKA) and (MKB) at different replacement ratios on compressive strength after (a) 7days, (b) 28 and (c) 90 days

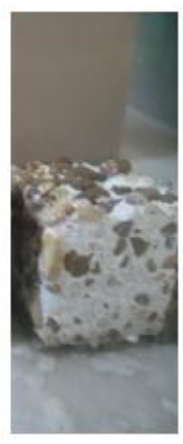

PC

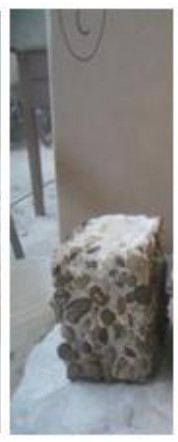

SR

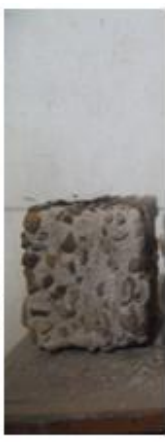

MKA20\%

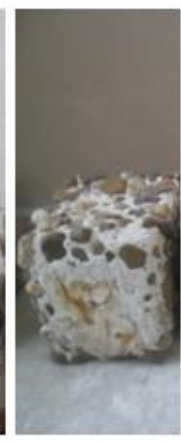

MKB15\%

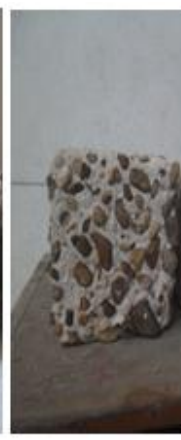

KBS15\%

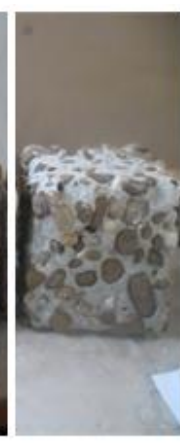

$\mathrm{SF} 20 \%$

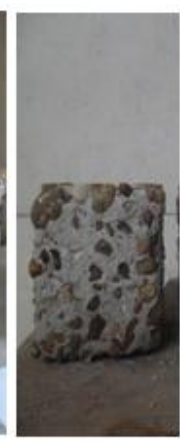

SFS20\%

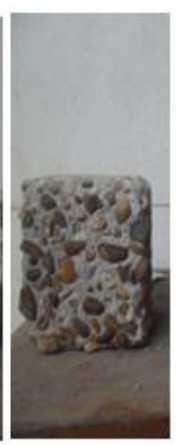

FB

Fig. 7. Concrete cubes after 90 days immersion in 3\% sulphuric acid.

It is clearly shown in Fig. (7) that after immersion both PC and SR concrete cubes had a surface layer of white paste. White colour indicated that Sulphuric acid exposure caused extensive formation of gypsum, calcium sulfate $(\mathrm{CaSO} 4,2 \mathrm{H} 2 \mathrm{O})$, in the surface of the specimens. As well-known that gypsum formation decreases the $\mathrm{pH}$ in concrete, and causes softening and expansion. Within 60 days of immersion the surface layer of the specimens was converted to some reactions products extended to a depth $3 \mathrm{~mm}$. After 90 days specimens deteriorated to a depth almost $6 \mathrm{~mm}$.

Almost similar to control appearance was observed for concrete specimens containing $15 \%$ of MKB and 20\% of MKA where, the depth of the deterioration was of 2.5 and 5.5 $\mathrm{mm}$ after 60 and 90 immersion days respectively. As for concrete specimens containing $20 \%$ of SF the deterioration after 60 days immersion was less severe in compared to other specimens where, the depth of the deterioration extended to a depth $2 \mathrm{~mm}$. While after 90 days specimens deteriorated to a depth almost $5 \mathrm{~mm}$. It is interested to note that the least deterioration was noted in specimens of concrete mixture FB. Where the gypsum layer formed on the cube surface as a result of exposure to acid less than other mixtures and a slight expansion of cement mortar noticed on the end surfaces.

\subsubsection{Mass loss over immersion time in sulphuric acid}

The mass loss of the specimens of selected concrete mixes after 30,60 and 90 days immersion in $3 \%$ sulphuric acid solution compared to their initial weight after 28 days of curing in potable water under laboratory conditions is illustrated figure (8).

It can be observed that from figure (8) the concrete mixt SR possessed the highest mass loss over the period of exposure to 3\% sulphuric acid. Although both SR and PC concrete cubes did 
Mohamed Sayed Essa et al., Effect of local metakaolin on properties of concrete and its sulphuric...

not showed any difference in resisting 3\% sulphuric acid attack, even further in the long-term exposure to acid, but the SR cubes had a negative effect compared to that for the control cubes.

Another observation was noticed a slight difference between two metakaolin mixes MKB15 and MKA20 on mass loss against exposure time. Also it can be said that both metakaolin mixes slightly improved the concrete resistance to 3\% sulphuric acid attack than control after any immersion time.

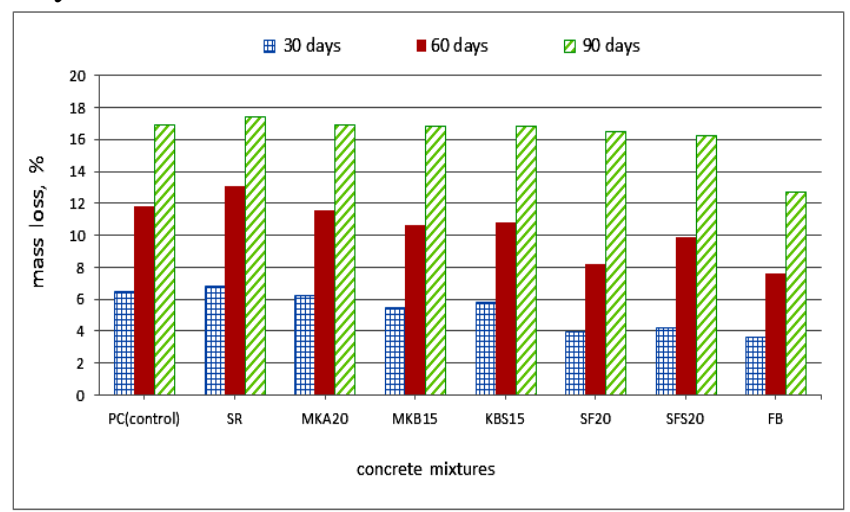

Fig. 8. Mass loss of selected concrete mixtures with exposure period in a $3 \%$ sulphuric acid solution.

It can also be observed that the $20 \%$ of SF significantly reduced the mass loss of concrete specimens after 30 and 60 days immersion in $3 \%$ sulphuric acid compared to that for control ones. While, after 90 days immersion SF20\% began to lose its effect to resistance to acid attack and the mass loss reached limits near to that of control samples. During the 30, 60 and 90 days immersion, the rates of mass loss for the SF20 specimens was achieved to be lower than those of the control specimens' by $40 \%, 31 \%$ and $2 \%$, respectively.

Also based on the obtained results it can be argued that, the effect of adding 20\% SF in concrete mix (SFS20) and 15\% of MKB in concrete mix (KBS15) as partial replacement of sulfate resistance cement resistant is similar to the effect of replacement by Ordinary Portland Cement for concrete resistance to 3\% sulphuric acid attack.

It was also noticed from figure (8) that the FB concrete mix exhibited the lowest mass loss compared to that for control and all used concrete mixes. A reduction of $45 \%, 35 \%$ and $25 \%$ than that for control mix, in mass loss of concrete specimens due to immersion 30, 60 and 90 days, respectively in $3 \%$ sulphuric acid solutions was achieved. This result is related to the incorporating combination of two admixtures $20 \%$ SF and 15\% MKB to the mixes.

\subsubsection{Strength reduction over immersion time in sulphuric acid}

Effect of various concrete mixes on reduction in compressive strength compared to their standard 28-day compressive strength with exposure period in 3\% sulfuric acid are shown in figure (9). As shown in figure (9) it should be noted that, the compressive strength reduction rate increased with the period of exposure to $3 \%$ sulfuric acid in all tested concrete mixes. The highest strength reduction was also noted for PC concrete specimens and almost similar to that for SR specimens. This means that there is no benefit from the use of sulphate resistant cement for the purpose of concrete resistance to sulfuric acid attack. This result is similar to what was reported by Schmidt et al. [15] in literature. 
Also it is interesting to add that the trend of results of strength reduction as a result of immersion in 3\% sulfuric acid were the same as the results that have been reached for the mass loss tests, where both metakaolin mixture MKB15 and MKA20 had a very slight improvement in decreasing the strength reduction compared to that for control over exposure period to the acid. SF20 concrete specimens indicate that strength reduction was decreased by $34 \%$ and $16 \%$ for 30 and 60 days immersion in 3\% sulfuric acid solution compared to control one, while by only $1.5 \%$ after 90 days of immersion. At the end of 90 days immersion in $3 \%$ sulfuric acid solution, the strength reduction of concrete mixes containing silica fume and both metakaolin was not significantly different from those for control mixture. This indicated that the concretes produced by using both metakaolins and silica fume are similar to that for concrete produced by using pure OPC when exposed to $3 \%$ sulfuric acid for a long time where a serious effect was noticed leading the concrete to lose their strengths.

It was also noticed that the FB concrete specimens had the best acid resistance among the eight mixes. FB concrete specimens showed a reduction in the strength reduction by $32 \%$, $15 \%$ and $14 \%$ due to immersion 30, 60 and 90 days in 3\% sulphuric acid, respectively. This indicated that the combination of $20 \%$ of silica fumes as partial replacement for OPC and blended with $15 \% \mathrm{MKB}$ enhanced the concrete resistance to sulphuric acid environment.

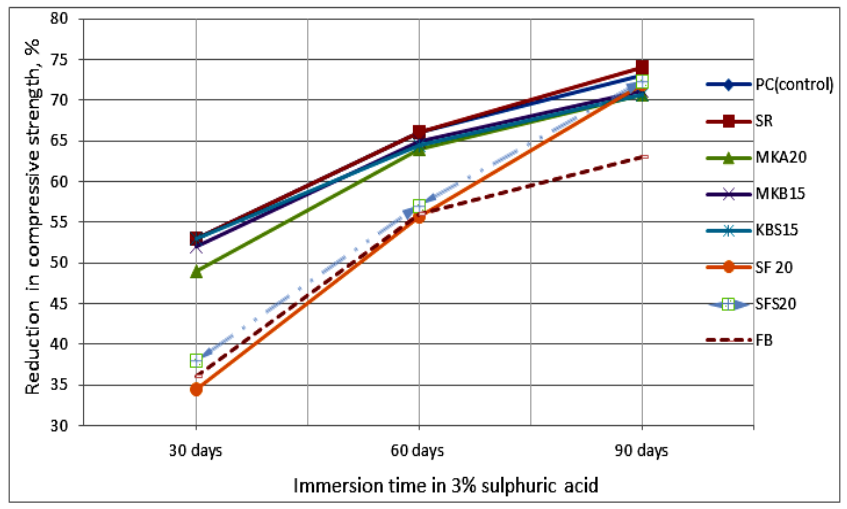

Fig. 9. Reduction in compressive strength of concrete specimens with exposure period in $3 \%$ sulfuric acid solution.

As mentioned in literature review on the effect of SCMs on the concrete resistance to sulfuric acid attack is contradictory. Our results are agree with what those of Mehta [16]; Durning and Hicks [17], who both found that the incorporation of silica fume increased the resistance of concrete to $1 \%$ sulfuric acid attack due to reduced calcium hydroxide content and lower permeability.

On the other hand, our results also are not compatible with what has been reported by Torii and Kawamura [18] and Hewayde [19]. This contradiction in the results could be attributed to the different used ratios of silica fume and concentrations of sulphuric acid used in these studies. Also in our study the minor effect of metakaolin in concrete resistance to sulphuric acid attack could be attributed to the low used smoothness of metakaolin in this study.

\section{Conclusions}

Based on the results obtained from the experiments, the following conclusions may be drawn:

1- With regard to workability, both local metakaolins MKA and MKB required less superplasticizer than that required for silica fume to achieve adequate concrete workability. Both metakaolins approximately required the same superplasticizer 
Mohamed Sayed Essa et al., Effect of local metakaolin on properties of concrete and its sulphuric...

dosage at the same ratio of cement replacement. The ratio $20 \%$ of Silica fumes required 200\% of superplasticizer more than that for the control while, $20 \%$ of both metakaolins required only $95 \%$ of superplasticizer more than the control.

2- Similar to silica fume Egyptian metakaolin can be considered as an effective pozzolanic mineral admixture that could be used in special concrete production purposes.

3- Local metakaolin replacement of cement is effective in improving the properties of fresh and hardened concrete. The optimum dosage of metakaolin, as a partial cement replacement is 15 to $20 \%$ for the used fineness in this study at W/Cm ratio 0.4 . It achieves an increase in compressive strength by $25 \%$ as compared to control ones, as well as it has the lowest water absorption.

4- Clearly notes that metakaolin have the same behavior to silica in the concrete porosity.

5- Neither SRC nor OPC concrete showed any difference in resisting 3\% sulphuric acid attack, even further in the long-term exposure to acid, the SRC concrete had a negative effect compared to that for the control one.

6- The effect of using silica fume and metakaolin, as partial replacement of SRC was similar to effect of replacement by OPC in concrete resistance to sulphuric acid attack.

7- The result of mass loss test was similar to the result of strength reduction in sulphuric acid attack. So it indicated that the mass loss test can be successively used in sulphuric acid attack test.

8- Concretes produced with metakaolin and silica fume have the same effect of concrete produced with pure OPC when exposed to $3 \%$ sulfuric acid for a long time

9- It was found that there is a beneficial effect of incorporating combination of two admixtures $20 \%$ silica fume and $15 \%$ metakaolin on concrete sulphuric acid resistance. It was achieved a reduction of $25 \%$ in mass loss than that for control mix, after immersion 90 days in $3 \%$ sulfuric acid.

10- Egyptian metakaolin may be considered better economically than silica fume, where the cost per ton of metakaolin does not exceed 700 pounds at the latest, while ton of silica fume cost exceeds 2600 pounds. Also metakaolin required less superplacticizer than that required for silica fume.

11- Using of metakaolin provides major economic benefits for cement, because metakaolin saves energy and reduces pollution of environment, where metakaolin is low cost and reduces the emission of carbon dioxide in the atmosphere.

\section{REFERENCES}

[1] Egyptian Code of practice, (2012), Permanent Committee For the code " Design and construction of reinforced concrete structures" Fourth Edition, Housing and Building research Center and Physical Planning, Cairo, Egypt, 2012.

[2] Mehta, P.K., "Pozzolanic and cementitios by-prpduction Concrete-another Look:"ACI,SP-114,1989.

[3] Zhang MH, Malhotra VM. Characteristics of a thermally activated aluminosilicate pozzolanic material and its use in concrete. Cement and Concrete Research 25(8):1713-25, 1995.

[4] Badogiannis, E., Kakali, G., Dimopoulou, G., Chaniotakis, E., Tsivilis, S., "Metakaolin as a main cement constituent: exploitation of poor Greek kaolins" Cement \& Concrete Composites 27, 197-203, 2005.

[5] Alaa M. Rashad, "Metakaolin as cementitious material: History, scours, production and composition" Construction and Building Materials 41 (2013) 303-318.

[6] Ding, J.T. and Li, Z.J. (2002), Effects of metakaolin and silica fume on properties of concrete, ACI Materials Journal, 99(4): 393-398.

[7] Khatib, J.M., Clay, R.M., "Absorption characteristics of metakaolin concrete" Cement and Concrete Research 34 (1), 19-29, 2004. 
[8] Vu, D.D., Stroeven, P. and Bui, V.B., "Strength and durability aspects of calcined kaolin blended Portland cement mortar and concrete" Cement and Concrete Composites, 23(6): 471-478, 2001.

[9] Neville A.M, Properties of Concrete (4th edition), Pearson Education Limited, 1995.

[10] Qian, X.Q. and Li, Z.J., "The relationships between stress and strain for high-performance concrete with metakaolin" Cement and Concrete Research, 31(11): 1607-1611, 2001.

[11] Siddique R, Klaus J., "Influence of metakaolin on the properties of mortar and concrete: a review" Appl Clay Sci, 43(3-4):392-400, 2009.

[12] Poon, C.S., Lam, L., Kou, S.C., Wong, Y.L. and Wong, R., "Rate of pozzolanic reaction of metakaolin in high-performance cement pastes" Cement and Concrete Research, 31(9): 1301-1306, 2001.

[13] Frİas, M. and Cabrera, J., "Pore size distribution and degree of hydration of metakaolincement pastes" Cement and Concrete Research, 30(4): 561-569, 2000.

[14] Khatib, J.M. and Wild, S., "Pore size distribution of metakaolin paste" Cement and Concrete Research, 26(10): 1545-1553, 1996.

[15] Schmidtm., Hormannk., Hofmannf., Wagnere. and Leimene, "Concrete with greater resistance to acid and biogenic sulphuric acid corrosion" Sonderdruck aus BetonwerkC FertigteilTechnik, Heft 4, 64-70, 1997.

[16] P.K. Mehta, "Studies on chemical resistance of low water/cement ratio cements" Cem. Concr. Res. 15 (6) (1985) 969-978.

[17] T. Durning, M. Hicks, "Using microsilica to increase concrete's resistance to aggressive chemicals" Concr. Int. 13 (3) (1991) 42-48.

[18] K. Torii, M. Kawamura, "Effects of fly ash and silica fume on the resistance of mortar to sulfuric acid and sulfate attack" Cem. Concr. Res. 24 (2) (1994) 361-370.

[19] Hewayde E, Nehdi ML, Allouche E, Nakhla G., "Using concrete admixture for sulfuric acid resistance" ICE Proc Constr Mater 160(1):25-35, 2007.

[20] S. Brunauer, P.H. Emmett, E. Teller, J. Am. Chem. Soc. 60 (1938) 309.

[21] P.H. Emmett, S. Brunauer, J. Am. Chem. Soc. 59 (1937) 1553. 
Mohamed Sayed Essa et al., Effect of local metakaolin on properties of concrete and its sulphuric...

تأثير الميتاكاولين المحلي على خواص الخرسانة ومقاومتها لحمض الكبريتيك

الملخص العربي

المتاكاولين كاضافة معدنية بوزو لاتية للأسمنت ماز ال يتم در استها في العديد من الابحاث على مستوى العالم.

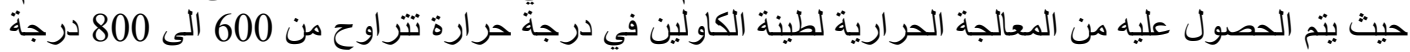

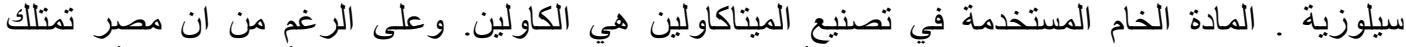

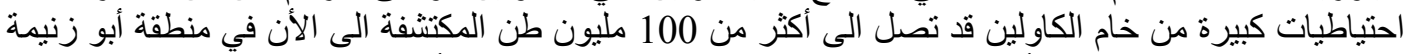

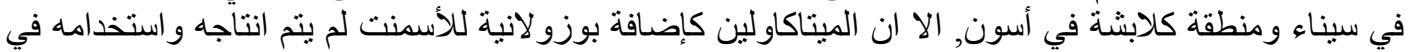

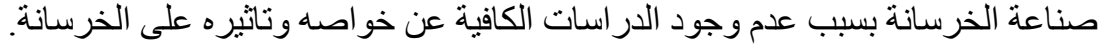

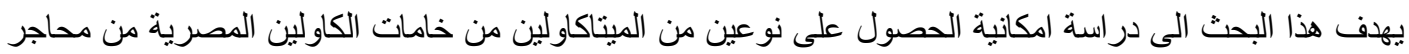

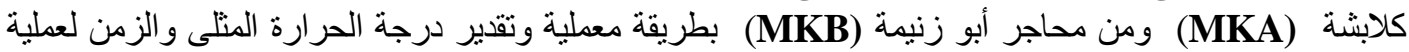

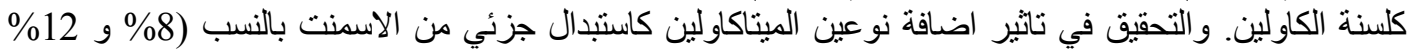

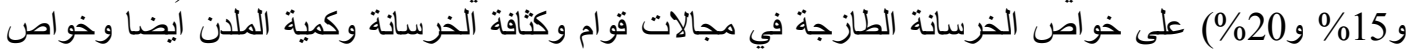

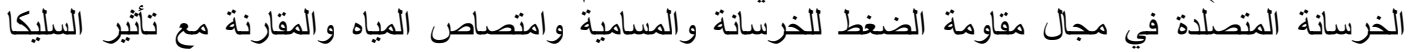

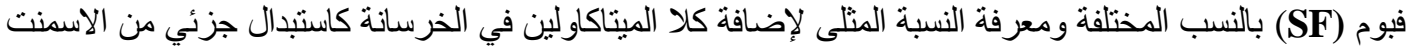

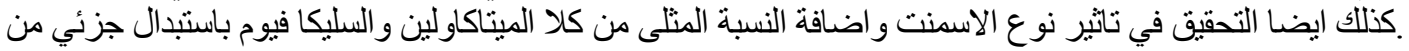

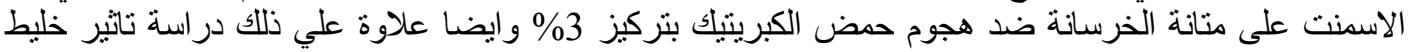
من MKB و SFB على مقاومة الضغط ومتانة الخرسانة.

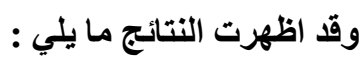

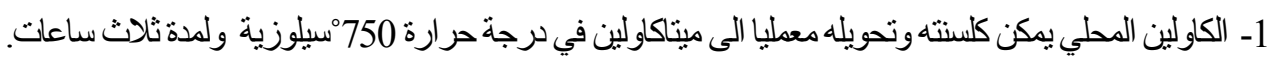

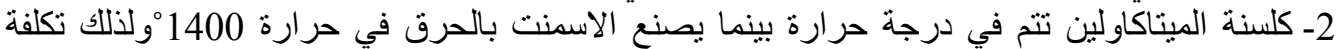

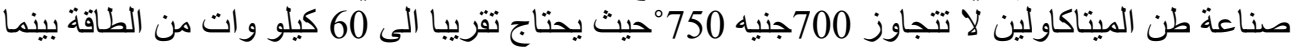

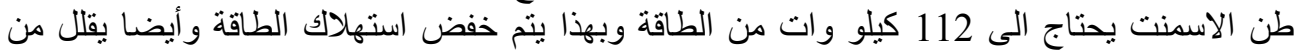

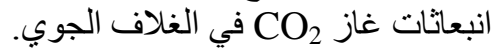

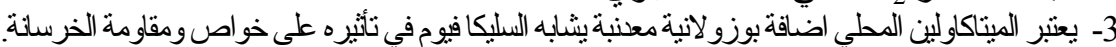

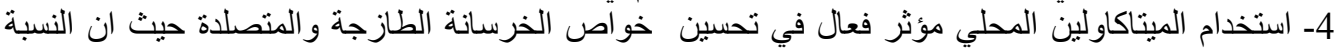

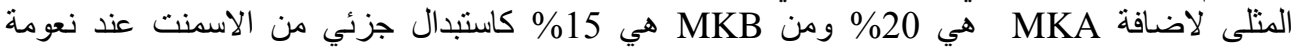

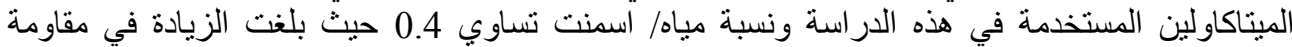

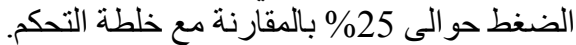

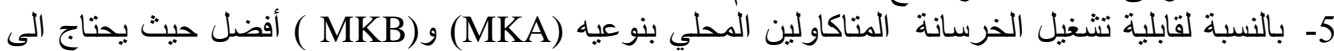

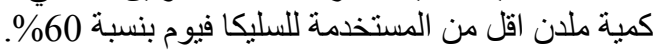
6- - كلا الميتاكاولين في كل نسب الاستبدال أفضل في الاداء من السليكا فيوم في اختبار امتصاص الخرسانة للمياه

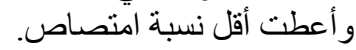

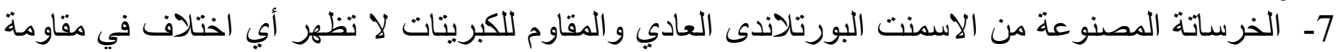

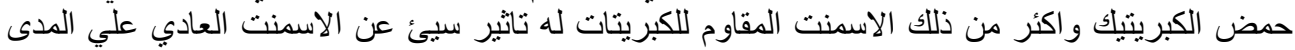

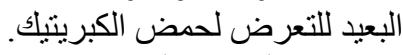

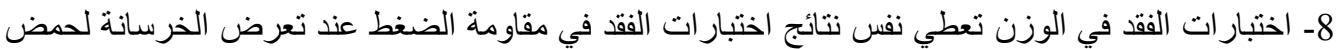

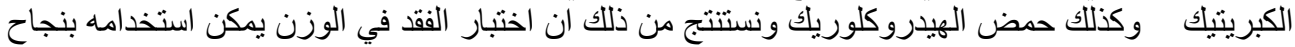

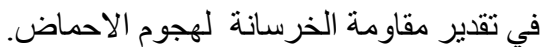

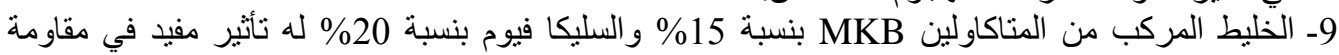

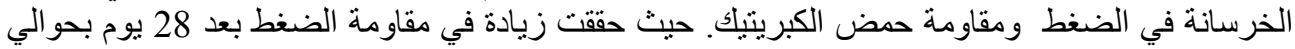

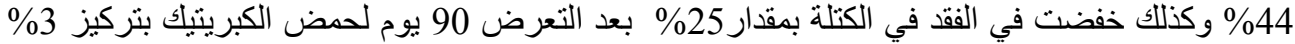
بالمقارنة مع خلطة التحكم. 10- الميتاكاولين المحلي افضل اقتصاديا من السليكا فيوم حيث ان طن الميتاكاولين لاتتجاوز تكلفته 700 جنيه بينما طن السليكا تكلفته تزيد عن افن الفين 2500 جنيه وكذلك يحتاج الى كمية ملدن أقل. 